
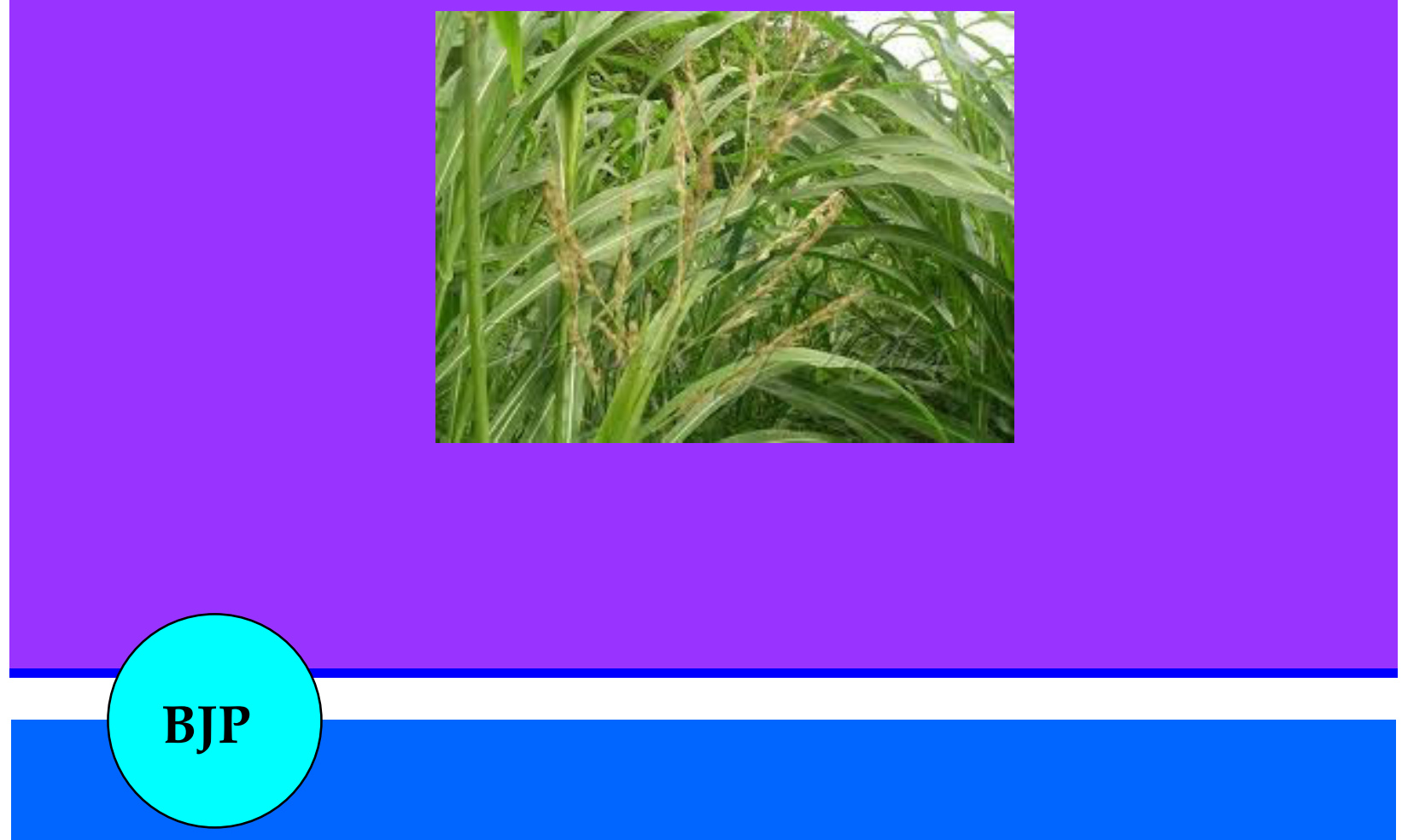

Bangladesh Journal of Pharmacology

Research Article

Phytochemical analysis, cytotoxic, antioxidant and anti-diabetic activities of the aerial parts of Sorghum halepense 


\title{
Phytochemical analysis, cytotoxic, antioxidant and anti-diabetic activities of the aerial parts of Sorghum halepense
}

\author{
Muhammad Abdur Rehman Shah, Rahmat Ali Khan and Mushtaq Ahmed \\ Department of Biotechnology, University of Science and Technology, Bannu 28100, KPK, Pakistan.
}

\begin{tabular}{|c|c|}
\hline Article Info & \\
\hline Received: & 18 February 2019 \\
\hline Accepted: & 2 August 2019 \\
\hline Available Online: & 21 August 2019 \\
\hline DOI: $10.3329 /$ bjp.v & $4 \mathrm{i} 3.40292$ \\
\hline $\begin{array}{l}\text { Cite this article: } \\
\text { Shah MAR, Khan } \\
\text { Phytochemical ar } \\
\text { antioxidant and an } \\
\text { of aerial parts of } \\
\text { Bangladesh J Pharr } \\
-51 \text {. }\end{array}$ & $\begin{array}{l}\text { RA, Ahmed M. } \\
\text { alysis, cytotoxic, } \\
\text {-diabetic activities } \\
\text { orghum halepense. } \\
\text { lacol. 2019; 14: } 144\end{array}$ \\
\hline
\end{tabular}

\begin{abstract}
Phytochemical screening, cytotoxic activity, total phenolic content, antioxidant and anti-diabetic activities of the Sorghum halepense methanolic extract and its different fractions were evaluated. Methanolic extract and its various fractions revealed the presence of reducing sugars, tannins, steroids, glycosides, flavonoids in the methanolic extract where they were absent in nhexane fraction except flavonoids. Gums and saponins were absent in all the samples. Methanolic extract indicated the highest cytotoxic $(80.7 \pm 1.3 \%)$ and anti-diabetic $(62.5 \%)$ activities. The maximum total phenolic contents $(28.7 \pm$ $1.4 \mathrm{mg} / \mathrm{mL}$ ) were found in the chloroform fraction. An aqueous fraction expressed the highest antioxidant activity 74.1 and $97.1 \%$ free radical scavenging properties in DPPH and ABTS assays respectively whereas, in the case of $\mathrm{H}_{2} \mathrm{O}_{2}$, methanolic extract indicated maximum (36.9\%) activity. In conclusion, the extract of aerial parts of $S$. halepense is a source of compounds against cancer, diabetic and free radical associated disorders.
\end{abstract}

\section{Introduction}

The damage caused by free radicals is the crucial ethological factor concerned with several chronic diseases such as cancer, atherosclerosis, diabetes mellitus, arthritis, and neurodegenerative diseases and also in the aging process. The epidemiological studies have revealed that the use of diets rich in fruits and vegetables and those containing selected natural antioxidants such as plant polyphenols, vitamin $\mathrm{C}$ and flavonoids are linked to reduced prevalence of cardiovascular and some cancerous chronic diseases (Gheldof and Engeseth, 2002; Liu et al., 2000; Siddhuraju and Becker, 2003; Zuo et al., 2002).

The anti-diabetic activities of Achillea santolina (Grover et al., 2002), Adiantum capillus-veneris (Al-Snafi, 2013), Agrimony eupatoria (Al-Snafi, 2015), Aristolochia longa (El Omari et al., 2019), Atractylis gummifera (Bouabid et al., 2019), Eruca sativa (Kishore et al., 2017), Gaultheria trichophylla (Alam and Saqib, 2017), Leucas aspera (Annapandian and Sundaram, 2017), Myrica gale,
Rhodiola rosea, Rumex acetosa, Taraxacum officinale (Sekhon-Loodu and Rupasinghe, 2019), Trixis angustifolia (Salazar-Gómez et al., 2019) and Urtica dioica (Ahangarpour et al., 2012) have been reported.

The antidiabetic effect of Sorghum bicolor (Chung et al., 2011) has been reported. However, the antidiabetic effect of $S$. halepense is not known.

The aim of this study was to investigate the phytochemicals, cytotoxic properties, total phenolic content, antioxidant and anti-diabetic properties of crude methanolic extract of aerial parts of $S$. halepense and its $n$ -hexane, chloroform and aqueous fractions through brine shrimp lethality, DPPH, ABTS and $\mathrm{H}_{2} \mathrm{O}_{2}$ assays and quantification of total phenolic content.

\section{Materials and Methods \\ Chemicals for biological activities}

Chemical reagents sodium phosphate monobasic, sodi- 
um phosphate dibasic, DPPH (2, 2-diphenyl-1-picrylhydrazyl), ABTS $\bullet+(2,2$-azinobis (3-ethyl-benzothiazoline)-6-sulfonic acid disodium salt), hydrogen peroxide, amylase, DNS (dinitrosalicylic) acid, sea salts, glucophage, potassium persulfate were of analytical grade. Methanolic extract and its $n$-hexane, chloroform and aqueous fractions of the aerial part of $S$. halepense. Biotechnology Medical Services (BMS, UV-1602) spectrophotometer was used for measuring absorbance.

\section{Plant material}

The aerial parts of S. halepense were collected in March 2017 from the District Bannu, Pakistan. It was identified by Prof. Abdur Rehman, Govt. Postgraduate College, Bannu, Khyber Pakhtoon Khwa, Pakistan.

\section{Preparation of crude extract}

The aerial parts of young $S$. halepense were collected, washed with tap water, dried under shade and ground into fine powder with the help of pestle and mortar. The powder $(600 \mathrm{~g})$ was extracted in $1.5 \mathrm{~L} 70 \%$ methanol by keeping the powder in mentioned solvents at room temperature with frequent agitation for 72 hours and the resultant liquid was filtered (Whatman No. 3 filter paper, Whatman Ltd., England). The filtrate was sited at room temperature to vanish the solvent content. The resultant gummy methanolic extract (26.8 g) was collected and stored for future use.

\section{Preparation of fractions}

Methanolic crude extract $(20 \mathrm{~g})$ of $S$. halepense was sequentially extracted each with $300 \mathrm{~mL} n$-hexane, chloroform and water using separating funnel to avoid any sort of damages to the filtrate. The respective solvents were evaporated completely at room temperature. The resulting extracts of $n$-hexane $(2 \mathrm{~g})$, chloroform $(3.2 \mathrm{~g})$ and water $(7.9 \mathrm{~g})$ were stored for further designed assays.

\section{Phytochemicals screening}

The methanolic extract of $S$. halepense and its different fractions were subjected to phytochemicals screening by using standard methods to investigate the presence of cardiac glycosides, saponins, flavonoids, tannins, steroids, reducing sugar and gums (Rice-Evans et al., 1996; Trease and Evans, 1989).

\section{Cytotoxic assay}

Methanolic extract and its various fractions of $S$. halepense were subjected to brine shrimp lethality bioassay to find out their cytotoxic activities (Meyer et al., 1982). A small amount of brine shrimp eggs (1 mg) were put in $4 \%$ artificial seawater contained in a cabin covered by aluminum foil and placed for 24 hours. After hatching, the shrimps crossed the porous central wall of the cabins and came into an illuminated one. The working solution of methanolic extract and its different fractions were prepared in methanol with different concentrations i.e. 100, 250, 500 and $1000 \mu \mathrm{g} /$ $\mathrm{mL}$. Test tubes containing test samples were placed at room temperature for complete evaporation of methanol followed by inoculation with 10 shrimps to each test tube and incubation for 24 hours. Then counted live shrimps in each test tube, calculated \%lethality with the help of Abbot's formula and compared the results (lethality) of control with experimental.

$\%$ Death $=[($ Sample - control $) /$ control $] \times 100$

\section{Total phenolic content}

The total phenolic content present in the methanolic extract and its fractions of $S$. halepense was determined by the method described elsewhere (Singleton and Rossi, 1965) with slight modification. The sample solution $(250 \mu \mathrm{L} ; 1-5 \mathrm{mg} / \mathrm{mL})$ was added to $2.5 \mathrm{~mL}$ Folin-Ciocalteu reagent $(10 \mathrm{x}$ diluted in distilled water) and incubated at room temperature for $5 \mathrm{~min}$. A saturated solution of $\mathrm{Na}_{2} \mathrm{CO}_{3}(2.5 \mathrm{~mL}, 60 \mathrm{mg} / \mathrm{mL})$ was mixed to the reaction mixture and placed again for 2 hours at the mentioned temperature. Gallic acid was used as the standard. Measured the absorbance at 725 $\mathrm{nm}$ spectrophotometrically and articulated the results as gallic acid equivalent. Gallic acid solutions $(1-5 \mathrm{mg} /$ $\mathrm{mL}$ ) were used to prepare the calibration curve and expressed the results as gallic acid equivalents (GAE).

\section{Antioxidant assays}

\section{ABTS radical cation assay}

The capability of methanolic extract and its various fractions of $S$. halepense to scavenge ABTS $\bullet+(2,20-$ azinobis (3-ethyl-benzothiazoline)-6-sulfonic acid disodium salt) free radicals was determined by making slight changes in (Re et al., 1999) protocol. Prepared ABTS $(7 \mathrm{mM})$ and potassium persulfate solutions $(2.45$ $\mathrm{mM})$, mixed together and placed for eight hours in dark. The mentioned stock solution was diluted with the relevant solvent $(50 \%)$ and adjusted its absorbance of about $0.900( \pm 0.02)$ at $745 \mathrm{~nm}$ at $30^{\circ} \mathrm{C} .300 \mu \mathrm{L}(125-$ $2000 \mu \mathrm{g} / \mathrm{mL}$ in a respective solvent) of each sample was mixed with ABTS working solution and measured the absorbance. The percentage scavenging property of samples applied and the ascorbic acid was calculated using the following formula:

Scavenging effect $(\%)=[($ control absorbance $(\mathrm{ABTS})$ sample absorbance) / (control absorbance) $] \times 100$

\section{Hydrogen peroxide scavenging $\left(\mathrm{H}_{2} \mathrm{O}_{2}\right)$ assay}

The hydrogen peroxide scavenging activities of $S$. halepense methanolic extract and its different fractions were estimated according to the protocol mentioned elsewhere (Wettasinghe and Shahidi, 2000) protocol. The prepared sample solutions $(125-2000 \mu \mathrm{g} / \mathrm{mL})$, phosphate buffer (100 mM, pH 7.4) and hydrogen peroxide solution $(43 \mathrm{mM})$ in the phosphate buffer. The 


\section{Box 1: DPPH Method}

\section{Principle}

A hydrogen donor is an anti-oxidant. It measures the compounds that are radical scavengers. DPPH • accepts hydrogen from an anti-oxidant. DPPH $\bullet$ is one of the few stable and commercially available organic nitrogen radicals. The anti-oxidant effect is proportional to the disappearance of $\mathrm{DPPH} \bullet$ in the test sample.

\section{Requirements}

Ascorbic acid, DPPH (1,1-diphenyl-2-picrylhydrazyl), Extract of S. halepense,

\section{Preparation of solutions}

Ascorbic acid: Working solutions (125, 250, 500, 1000, 1500 and $2000 \mu \mathrm{g} / \mathrm{mL}$ ) of ascorbic acid were prepared.

Extract: Working solutions (125, 250, 500, 1000, 1500 and 2000 $\mu \mathrm{g} / \mathrm{mL}$ ) of methanolic extract and its different fractions were prepared.

DPPH solution: The DPPH solution was prepared by dissolving $3 \mathrm{mg}$ of it in $100 \mathrm{~mL}$ methanol.

\section{Procedure}

Step 1: The DPPH solution was incubated for about $30 \mathrm{~min}$ at $25^{\circ} \mathrm{C}$ in the dark.
Step 2: The absorbance was measured at $517 \mathrm{~nm}$ (purple color) spectrophotometrically and adjusted it to less than one. The color turns from purple to yellow followed by the formation of DPPH upon absorption of hydrogen from an anti-oxidant.

Step 3: Then mixed sample/standard and DPPH solutions and recorded absorbance.

\section{Calculation}

The potential of plant extracts to scavenge DPPH free radicals was calculated by using the following equation.

$\% \mathrm{DPPH}$ free radicals scavenging effect $=\left(\mathrm{A}_{1}-\mathrm{A}_{2} / \mathrm{A}_{1}\right) \times 100$

Where, $\mathrm{A}_{1}=$ the absorbance of DPPH (control) and

$$
\mathrm{A}_{2}=\text { the absorbance in the presence of samples }
$$

Notes

1. Wear gloves while handling DPPH solution

2. Lab coat and goggles should be used

3. Work in fume hood

4. DPPH is stored in the freezer. It should be protected from light and the time out of the freezer should be minimized

\section{References}

Gyamfi et al., 1999; MacDonald-Wicks et al., 2006; Moon and Shibamoto, 2009

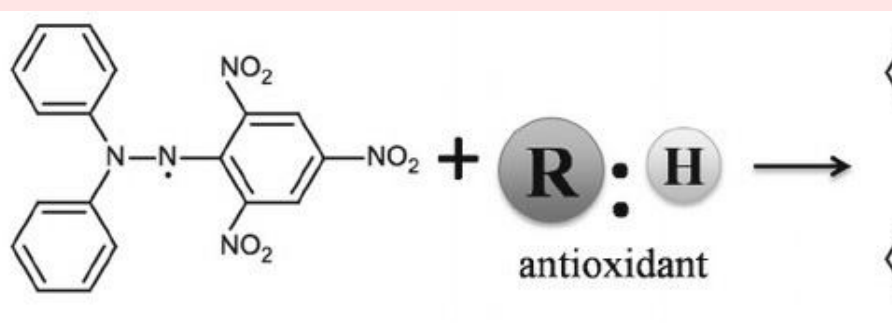

DPPH

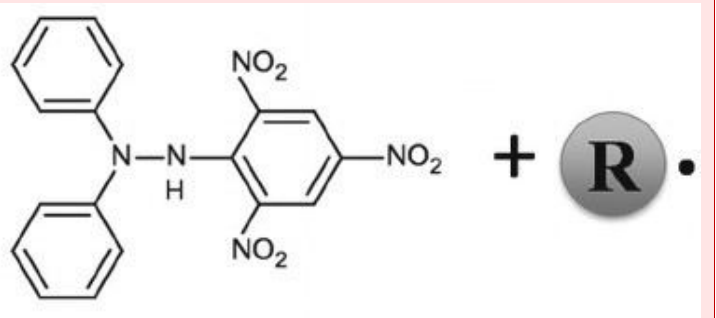

DPPH-H

Purple, $519 \mathrm{~nm}$

Colorless

absorbance of the reaction mixture was measured at 230 $\mathrm{nm}$ against a blank containing $\mathrm{H}_{2} \mathrm{O}$ instead of $\mathrm{H}_{2} \mathrm{O}_{2}$ after its incubation for $40 \mathrm{~min}$ at room temperature. The following formula was to calculate the percentage of scavenging activities of plant extract.

Scavenging effect $(\%)=\left[\right.$ (control absorbance $\left(\mathrm{H}_{2} \mathrm{O}_{2}\right)$ sample absorbance) / (control absorbance) $] \times 100$

All tests were conducted in triplicate and articulated the results as means $\pm \mathrm{SD}$.

\section{a-Amylase inhibition}

The inhibitory properties of plant extract against aamylase were investigated by using Worthington Enzyme Manual Worthington (Kwon et al., 2007) guideline. Plant extract $(300 \mu \mathrm{L})$, starch $(500 \mu \mathrm{L}$; $1 \%)$ and a-amylase solutions $(0.5 \mathrm{mg} / \mathrm{mL})$ were mixed and pre-incubated at $25^{\circ} \mathrm{C}$ for $10 \mathrm{~min}$. The enzymatic reaction was stopped by the addition of $1.0 \mathrm{~mL}$ of dinitrosalicylic (DNS) acid, a color reagent, incubated in the boiling water for $5 \mathrm{~min}$ and then cooled to room temperature. The starch, a-amylase and DNS acid solutions were prepared in sodium phosphate buffer (20 $\mathrm{mM}, \mathrm{pH} 6.9$ with $6 \mathrm{mM} \mathrm{NaCl}$ ). The reaction mixture was diluted by adding $3 \mathrm{~mL}$ distilled water to each test tube and measured the absorbance at $540 \mathrm{~nm}$ spectrophotometrically. The following formula was used to calculate the percentage inhibition of a-amylase.

Amylase inhibition (\%) $=[$ (control absorbance (blank)sample absorbance) / (control absorbance) $] \times 100$

\section{Statistical analysis}

The statistical analyses of results were carried out by using GraphPad Prism software. All the experiments were conducted in triplicate and articulated the results as mean \pm SD (standard deviation). Pearson correlation 
coefficient was determined in further analyses of results between total phenolic contents and different antioxidant and anti-diabetic activities. The $\mathrm{p}<0.05$ was considered to be statistically significant.

\section{Results}

\section{Phytochemical screening}

The phytochemical screening of $S$. halepense methanolic extract and its various fractions revealed the presence of reducing sugars, tannins, steroids, glycosides, flavonoids in the methanolic extract whereas they were absent in the $n$-hexane fraction except flavonoids (Table I). Gums and saponins were absent in all the samples.

\section{Cytotoxic assay}

The cytotoxic activities using brine shrimps lethality assay showed $80.7 \pm 1.3,60.3 \pm 1.1,50.4 \pm 1.6$ and $40.6 \pm$ $1.5 \%$ dead brine shrimp in crude methanolic extract and its chloroform, aqueous and $n$-hexane fractions respectively at the concentration of $1,000 \mu \mathrm{g} / \mathrm{mL}$ (Table II).

\section{Total phenolic contents}

The maximum amount of phenolic contents was observed in chloroform fraction $(28.7 \pm 1.4 \mathrm{mg} \mathrm{GAE} / \mathrm{g})$ followed by methanol $(22.5 \pm 1.3 \mathrm{mg} \mathrm{GAE} / \mathrm{g})$, aqueous $(15.1 \pm 1.3 \mathrm{mg} \mathrm{GAE} / \mathrm{g})$ and $n$-hexane fraction $(5.6 \pm 1.4$ $\mathrm{mg}$ GAE/g).

\section{Antioxidant assays}

\section{DPPH (1,1-diphenyl-2-picrylhydrazyl) method}

The aqueous fraction indicated highest antioxidant activity $(74.1 \%)$ followed by crude methanolic extract $(73.5 \%)$ and hexane fraction $(32.9 \%)$ whereas chloroform revealed lowest activity $(24.6 \%)$ at the concentrations of $2 \mathrm{mg} / \mathrm{mL}$. Ascorbic acid expressed $86.4 \%$ antioxidant activity at the same concentration. The antioxidant characteristics of $S$. halepense methanolic extract and its different fractions were concentrationdependent.

\section{ABTS-radical cation assay}

The highest antioxidant activity was revealed by an aqueous fraction $(97.1 \%)$ followed by crude methanolic extract $(96.7 \%)$ and chloroform fraction $(79.0 \%)$ while the said activity was not observed in $n$-hexane fraction. The mentioned activity of aqueous fraction (97.1\%) was comparable with ascorbic acid $(96.2 \%)$ (Figure 1). An indirect correlation was observed between phenolic contents and antioxidant activities of the applied samples, the chloroform fraction exhibiting maximum phenolic contents $(28.7 \pm 1.4 \mathrm{mg} / \mathrm{mL})$ expressed minimum antioxidant activity (79.0\%), the methanolic extract had moderate phenolic contents $(22.5 \pm 1.3 \mathrm{mg} /$ $\mathrm{mL}$ ) had shown moderate antioxidant activity (96.7\%).

\section{Hydrogen peroxide scavenging $\left(\mathrm{H}_{2} \mathrm{O}_{2}\right)$ capacity}

Table I

Phytochemical screening of S. halepense methanolic extract and its chloroform and aqueous fractions

\begin{tabular}{lllccc|} 
& & \multicolumn{3}{c}{ Crude methanolic extract and its fractions } \\
\cline { 2 - 5 } Phytochemical & Tests & Aqueous & Methanol & Chloroform & $n$-Hexane \\
\hline Saponins & Alkaline reagent test & - & - & - & - \\
Flavonoids & Ferric chlorides test & + & + & + & + \\
Glycosides & Fehling test & + & + & + & - \\
steroids & Millon's test & + & + & + & - \\
Reducing sugar & Benedict's test & + & + & - \\
Tannins & Ferric chloride test & + & - & - \\
Gums & Molish's reagent test & - & & + \\
\end{tabular}

Table II

\%Lethality of brine shrimps caused by crude methanolic extract and its various fractions of S. halepense

\begin{tabular}{|cccccr|}
\hline \multirow{2}{*}{$\begin{array}{c}\text { Concentration } \\
(\mu \mathrm{g} / \mathrm{mL})\end{array}$} & \multicolumn{5}{c|}{ \%ethality of crude methanolic extract and its fractions } \\
\cline { 2 - 6 } & Methanolic extract & Chloroform & Aqueous & $n$-Hexane & Control \\
\hline 100 & $40.7 \pm 1.3$ & $30.6 \pm 1.2$ & $20.3 \pm 1.5$ & $10.2 \pm 1.7$ & $00 \pm 00$ \\
250 & $50.8 \pm 1.5$ & $30.8 \pm 1.1$ & $30.9 \pm 1.3$ & $10.3 \pm 1.6$ & $00 \pm 00$ \\
500 & $70.6 \pm 1.7$ & $50.4 \pm 1.8$ & $30.1 \pm 1.5$ & $30.7 \pm 1.9$ & $10.2 \pm 1.1$ \\
1000 & $80.7 \pm 1.3$ & $60.3 \pm 1.1$ & $50.4 \pm 1.6$ & $40.6 \pm 1.5$ & $00 \pm 00$ \\
\hline
\end{tabular}




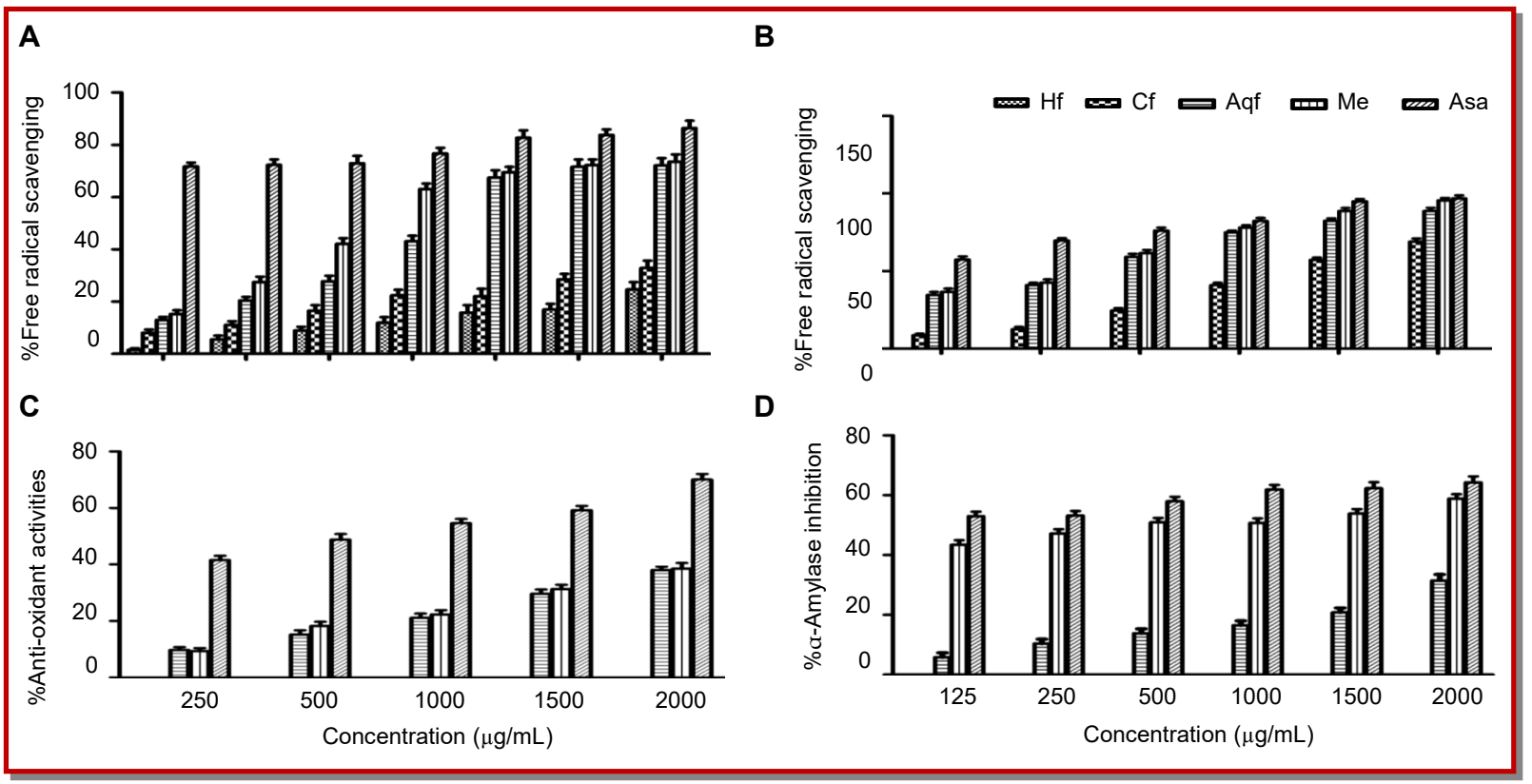

Figure 1: DPPH free radical scavenging capability (A), ABTS free radical scavenging capability (B), $\mathrm{H}_{2} \mathrm{O}_{2}$ free radical scavenging capability (C) and anti-diabetic activity (D) of the S. halepense methanolic extract and its fractions;

Hf: n-Hexane fraction, Cf: chloroform fraction, Me: methanolic extract, Aqf: aqueous fraction and Asa: ascorbic acid; n-hexane fraction did not show anti-oxidant activity in B; hexane fraction and Cf: chloroform fraction did not show anti-oxidant activities in C; hexane fraction and Aqf: aqueous fraction did not express anti-diabetic activities in D

\begin{tabular}{|lcc|}
\hline \multicolumn{3}{|c|}{ Table III } \\
\hline \multicolumn{3}{|c|}{ Correlation between phenolics and S. halepense } \\
extract soluble fractions \\
Assays & $\begin{array}{c}\text { Correlation } \mathrm{R}^{2} \\
\text { phenolics }\end{array}$ & $\begin{array}{c}\text { Signifi- } \\
\text { cance }\end{array}$ \\
\hline $\begin{array}{l}\text { \%DPPH radical scavenging } \\
\text { ability }\end{array}$ & 0.5 & $\mathrm{~ns}$ \\
\%ABTS scavenging ability & 0.6 & $\mathrm{~ns}$ \\
\% $\mathrm{H}_{2} \mathrm{O}_{2}$ scavenging & 0.9 & $\mathrm{~ns}$ \\
\% Alpha-amylase inhibition & 0.8 & $\mathrm{~ns}$ \\
\hline
\end{tabular}

The applied extract sample of $S$. halepense expressed scavenging of $\mathrm{H}_{2} \mathrm{O}_{2}$ in a concentration-dependent manner. The crude methanolic extract and its water fraction indicated 36.9 and $36.5 \%$ scavenging activity respectively on hydrogen peroxide while ascorbic acid showed $51.0 \%$ at the concentration of $2000 \mu \mathrm{g} / \mathrm{mL}$. The chloroform and $n$-hexane fraction did not express $\mathrm{H}_{2} \mathrm{O}_{2}$ scavenging activities (Figure 1 ).

\section{Anti-diabetic assay}

Crude methanolic extract and its different fractions of $S$. halepense were subjected to an anti-diabetic assay to assess their anti-diabetic properties (Figure 1). The said characteristic of glucophage (commercially available medicine used as a standard) and crude methanolic extract were observed $(48.9 \%)$ and $(62.5 \%)$ respectively.

Correlation among total phenolic contents, anti-

\section{oxidant and anti-diabetic activities}

Chloroform fraction exhibited maximum phenolic content $(28.7 \pm 1.4 \mathrm{mg}$ GAE), with minimum DPPH and ABTS free radical scavenging properties while did not show anti-diabetic and hydrogen peroxide radicals scavenging activities (Table III).

\section{Discussion}

The phytochemical assessment of aerial parts of young $S$. halepense extract and its diverse fractions showed the existence of reducing sugars, tannins, steroids, glycosides, flavonoids in the methanolic extract where they were absent in $n$-hexane fraction except flavonoids. Gums and saponins were absent in all samples. Aerial parts of young $S$. halepense methanolic extract and its chloroform, aqueous and n-hexane fractions showed brine shrimp lethality up to $80.7 \pm 1.3 \%$, $60.3 \pm 1.1 \%$, $50.4 \pm 1.6 \%$ and $40.6 \pm 1.5 \%$ respectively at a concentration of $1000 \mu \mathrm{g} / \mathrm{mL}$. Different results were observed in different antioxidant assays i.e. aqueous fraction expressed highest antioxidant activity $74.1 \%$ and $97.1 \%$ free radical scavenging properties in DPPH and ABTS respectively whereas in case of $\mathrm{H}_{2} \mathrm{O}_{2}$ methanolic extract indicated maximum (36.9\%) activity. It is found that plant extracts with higher total phenolic contents have lower antioxidant properties. Aerial parts of young $S$. halepense methanolic extract and its different fractions were subjected to amylase inhibition assay to find out 
their anti-diabetic properties. The anti-diabetic activities of glucophage (used as a standard) and methanolic extract of aerial parts of young $S$. halepense were recorded $(48.9 \%)$ and $(62.5 \%)$ respectively. The higher anti-diabetic behavior of methanolic extract than glucophage indicates that the mentioned extract is an effective source of anti-diabetic compounds. Dose-dependent percentage inhibition of alpha amylase was observed.

The major chemical constituents of $S$. halepense are sorgoleone and dihydrosorgoleone (Baerson et al., 2008).

Comparable phytochemicals constituents were observed in various extracts of leaves of T. chebula (Kathirvel and Sujatha, 2012). The reported cytotoxic activities of Calligonum polygonoides (Khan et al., 2015) and Solanum surrantance burm (Shah et al., 2013). Arcangelisia flava, Coscinium blumeanum and Fibraurea tinctoria (Keawpradub et al., 2005) are harmonious with our results. Previously, unlike antioxidant results have reported in different antioxidant assays (Hagerman et al., 1998). Our results are congruent with earlier studies which reported indirect relations between phenolic content and antioxidant activities exhibited by plant extracts (Kahkonen et al., 1999; Ismail et al., 2004). Our results resemble with curry tree and petai that contained high total phenolic content but lower anti-oxidant activities (Wong et al., 2006). Many previous studies have reported anti-diabetic properties and antioxidant activities of phenolic compounds in different parts of medicinal plants (Krings and Berger, 2001; Samal, 2013). Resembling dose-dependent and higher anti-diabetic results were revealed by the extract of $P$. guajava leaves in vitro (Manikandan et al., 2016).

Phytochemical assessment of plant extract and its different fractions revealed the presence of various phyto constituents that demonstrated specific therapeutic effects. Further study of plant extract is dependent on the presence of these compounds. Phenolic compounds, like flavonoids and terpenoids are the major antioxidants that exercise scavenging of free radicals and hence neutralization of reactive oxygen species (Hossain et al., 2011). Flavonoids use several mechanisms such as scavenging of free radicals and the inhibitions of enzymes involved in the production of free radicals and thus prevent the development of oxidative stress (Benavente-García et al., 1997). Usually the phytochemicals are extracted in different solvents where each one has specific influence on the extraction of said constituents depending on the nature of solvent and its interface with desired compounds. Therefore, the extracted compounds and their dry weight will be variable extracted in various solvents ( $\mathrm{Li}$ et al. 2006; Pereira et al., 2008; Zhang et al., 2009). The cytotoxic findings imply that the assessed extracts are probable potential sources of antimicrobial and anticancer compounds. The differences observed in scavenging behavior of test sample and its fractions against various free radicals system may depict that different oxidation reduction mechanisms are involved in the different assays. The higher free radical scavenging activity of aerial parts of young $S$. halepense aqueous fraction and methanolic extract to forage more free radicals ( ABTS +) might be owing to higher molecular weight phenolics (tannins) and their convenience depends on molecular weight, the number of aromatic rings and nature of hydroxyl group's exchange than the explicit functional groups. Various antioxidant compounds such as $\beta$-carotene, tocopherol, selenium, vitamin $C$ or phenolic compounds perform in different ways with divers mechanisms (Ismail et al., 2004). Serious health problems like obesity and diabetic results from metabolic disorder of carbohydrates. Problems in insulin secretion or deterioration in its function decreases the breakdown of disaccharides and polysaccharides and eventually cause the onset of diabetes mellitus (Funke and Melzig, 2006). Inhibition of alpha amylase, an enzyme responsible for digestion of carbohydrate slows down the process of carbohydrate digestion and hence reduce the uptake of glucose by intestines (Cheng and Fantus, 2005). Searching of natural inhibitor of amylase can be conducted by in vitro amylase inhibition assay and hence ultimate estimation of anti-diabetic characteristics of plant extracts.

\section{Conclusion}

The aerial parts of young $S$. halepense contain considerable cytotoxic, antioxidant and anti-diabetic properties. The chloroform fraction exhibited maximum phenolic contents but minimum antioxidant activities.

\section{Conflict of Interest}

The author declares that no conflict of interests.

\section{Acknowledgement}

We are thankful to all my friends and colleague who guided us.

\section{References}

Ahangarpour A, Mohammadian M, Dianat M. Antidiabetic effect of hydroalcholic Urtica dioica leaf extract in male rats with fructose-induced insulin resistance. Iranian J Med Sci. 2012; 37: 181.

Alam F, Saqib QN. Antidiabetic potential of Gaultheria trichophylla in mice. Bangladesh J Pharmacol. 2017; 12: 29298.

Al-Snafi A E. Chemical constituents and pharmacological activities of milfoil (Achillea santolina). A Review. Int J Pharm 
Tech Res. 2013; 5: 1373-77.

Al-Snafi A E. The pharmacological and therapeutic importance of Agrimonia eupatoria: A review. Asian J Pharm Sci Technol. 2015; 5: 112-17.

Annapandian V, Sundaram RS. In vitro antidiabetic activity of polar and nonpolar solvent extracts from Leucas Aspera (Willd.) link leaves. Pharmacogn Res. 2017; 9: 261-65.

Baerson SR, Dayan FE, Rimando AM, Nanayakkara NP, Liu CJ, Schröder J, Fishbein M, Pan Z, Kagan IA, Pratt $\mathrm{LH}$, Cordonnier-Pratt MM, Duke SO. A functional genomics investigation of allelochemical biosynthesis in Sorghum bicolor root hairs. J Biol Chem. 2008; 283: 3231-47.

Benavente-García O, Castillo J, Marin FR, Ortuño A, Del Río JA. Uses and properties of citrus flavonoids. J Agric Food Chem. 1997; 45: 4505-15.

Bouabid K, Lamchouri F, Toufik H, Boulfia M, Senhaji S, Faouzi ME. In vivo anti-diabetic effect of aqueous and methanolic macerated extracts of Atractylis gummifera. Bangladesh J Pharmacol. 2019; 14: 67-73.

Cheng AY, Fantus IG. Oral antihyperglycemic therapy for type 2 diabetes mellitus. Can Med Assoc J. 2005; 172: 213-26.

Chung IM, Kim EH, Yeo MA, Kim SJ, Seo MC, Moon HI. Antidiabetic effects of three Korean sorghum phenolic extracts in normal and streptozotocin-induced diabetic rats. Food Res Int. 2011; 44: 127-132.

El Omari N, Sayah K, Fettach S, El Blidi O, Bouyahya A, Faouzi MEA, Barkiyou M. Evaluation of in vitro antioxidant and antidiabetic activities of Aristolochia longa extracts. Evid Based Complement Altern Med. 2019; 2019.

Funke I, Melzig MF. Traditionally used plants in diabetes therapy: Phytotherapeutics as inhibitors of alpha-amylase activity. Rev Bras Farmacogn. 2006; 16: 1-5.

Gheldof N, Engeseth NJ. Anti-oxidant capacity of honeys from various floral sources based on the determination of oxygen radical absorbance capacity and inhibition of in vitro lipoprotein oxidation in human serum samples. J Agric Food Chem. 2002; 50: 3050-55.

Grover J, Yadav S, Vats V. Medicinal plants of India with antidiabetic potential. J Ethnopharmacol. 2002; 81: 81-100.

Gyamfi MA, Yonamine M, Aniya Y. Free-radical scavenging action of medicinal herbs from Ghana: Thonningia sanguinea on experimentally-induced liver injuries. Gen Pharmacol. 1999; 32: 661-67.

Hagerman AE, Riedl KM, Jones GA, Sovik KN, Ritchard NT, Hartzfeld PW, Riechel TL. High molecular weight plant polyphenolics (tannins) as biological antioxidants. J Agric Food Chem. 1998; 46: 1887-92.

Hossain MA, Shah MD, Gnanaraj C, Iqbal M. In vitro total phenolics, flavonoids contents and antioxidant activity of essential oil, various organic extracts from the leaves of tropical medicinal plant Tetrastigma from Sabah. Asian Pac J Trop Biomed. 2011; 4: 717-21.

Ismail A, Marjan ZM, Foong CW. Total antioxidant activity and phenolic content in selected vegetables. Food Chem. 2004; 87: 581-86.
Kahkonen MP, Hopia AI, Vuorela HJ, Rauha JP, Pihlaja K, Kujala TS, Heinonen M. Antioxidant activity of plant extracts containing phenolic compounds. J Agric Food Chem. 1999; 47: 3954-62.

Kathirvel A, Sujatha V. In vitro assessment of antioxidant and antibacterial properties of Terminalia chebula Retz. leaves. Asian Pac J Trop Biomed. 2012; 2: 788-95.

Keawpradub N, Dej-adisai S, Yuenyongsawad S. Antioxidant and cytotoxic activities of Thai medicinal plants named Khaminkhruea: Arcangelisia flava, Coscinium blumeanum and Fibraurea tinctoria Songklanakarin. J Sci Technol. 2005; 27: 455-67.

Khan A, Khan RA, Ahmed M, Mushtaq N. In vitro antioxidant, antifungal and cytotoxic activity of methanolic extract of Calligonum polygonoides. Bangladesh J Pharmacol. 2015; 10: 316-20.

Kishore L, Kaur N, Kajal A, Singh R. Extraction, characterization and evaluation of Eruca sativa against streptozotocin-induced diabetic nephropathy in rat. Bangladesh J Pharmacol. 2017; 12: 216-27.

Krings U, Berger R. Antioxidant activity of some roasted foods. Food Chem. 2001; 72: 223-29.

Kwon YI, Apostolidis E, Shetty K. Evaluation of pepper (Capsicum annuum) for management of diabetes and hypertension. J Food Biochem. 2007; 31: 370-85.

Li BB, Smith B, Hossain MM. Extraction of phenolics from citrus peels: II. Enzyme-assisted extraction method. Sep Purif Technol. 2006; 48: 189-96.

Liu S, Manson JE, Lee IM, Cole SR, Hennekens $\mathrm{CH}$, Willett WC, Buring JE. Fruit and vegetable intake and risk of cardiovascular disease: The Women's health study. Am J Clin Nutr. 2000; 72: 922-28.

MacDonald-Wicks LK, Wood LG, Garg ML. Methodology for the determination of biological antioxidant capacity in vitro: A review. J Sci Food Agric. 2006; 86: 2046-56.

Manikandan R, Anand AV, Kumar S. Phytochemical and in vitro anti-diabetic activity of Psidium guajava leaves. Pharmacogn J. 2016; 8; 392-94.

Meyer BN, Ferrigni NR, Putnam JE, Jacobsen LB, Nichols DE, McLaughlin JL. Brine shrimp: A convenient general bioassay for active plant constituents. Planta Med. 1982; 45: 31-34.

Moon JK, Shibamoto T. Antioxidant assays for plant and food components. J Agric Food Chem. 2009; 57: 1655-66.

Pereira JA, Oliveira I, Sousa A, Ferreira ICFR, Bento A, Estevinho L. Bioactive properties and chemical composition of six walnut (Juglans regia L.) cultivars. Food Chem Toxicol. 2008; 46: 2103-11.

Re R, Pellegrini N, Proteggente A, Pannala A, Yang M, RiceEvans C. Antioxidant activity applying an improved ABTS radical cation decolorization assay. Free Radic Biol Med. 1999; 26: 1231-37.

Rice-Evans CA, Miller NJ, Paganga G. Structure-antioxidant activity relationships of flavonoids and phenolic acids. Free Radic Biol Med. 1996; 20: 933-56. 
Salazar-Gómez A, Vargas-Díaz ME, Garduño-Siciliano L. Hypoglycemic potential of Trixis angustifolia aqueous extract in alloxan-induced diabetic mice. Bangladesh J Pharmacol. 2019; 14: 74-79.

Samal PK. Antioxidant activity of Strobilanthes asperrimus in albino rats. Asian J Pharm Res. 2013; 3: 71-74.

Sekhon-Loodu S, Rupasinghe H. Evaluation of antioxidant, antidiabetic and antiobesity potential of selected traditional medicinal plants. Front Nutr. 2019; 6: 53.

Shah MAR, Khan H, Khan S, Muhammad N, Ullah Khan F, Shahnaz, Muhammad A, Khan YM. Cytotoxic, anti-oxidant and phytotoxic effect of Solanum surattense Burm F fruit extracts. Int J Pharmacogn Phytochem. 2013; 28: 1154-58.

Siddhuraju P, Becker K. Anti-oxidant properties of various solvent extracts of total phenolic constituents from three different agroclimatic origins of drumstick tree (Moringa oleifera Lam.) leaves. J Agric Food Chem. 2003; 51: 2144-55.
Singh HP, Batish DR, Kohli R. Allelopathy in agroeco-systems: An overview. J Crop Prod. 2001; 4: 1-41.

Singleton V, Rossi JA. Colorimetry of total phenolics with phosphomolybdic-phosphotungstic acid reagents. Am J Enol Vitic. 1965; 16: 144-58.

Trease GE, Evans WC. Phytochemical screening. Pharmacognsy. 11th ed. London, Macmillian Publishers, 1989, pp 45 -50 .

Wettasinghe M, Shahidi F. Scavenging of reactive-oxygen species and DPPH free radicals by extracts of borage and evening primrose meals. Food Chem. 2000; 70: 17-26.

Wong SP, Leong LP, Koh JHW. Anti-oxidant activities of aqueous extracts of selected plants. Food Chem. 2006; 99: $775-83$.

Zhang Z, Liao L, Moore J, Wu T, Wang Z. Anti-oxidant phenolic compounds from walnut kernels (Juglans regia L.). Food Chem. 2009; 113: 160-65. 